\title{
Decolonisation, representation and ethics in visual life stories from the Jungle
}

Aura Lounasmaa, Cigdem Esin and Crispin Hughes

\begin{abstract}
This paper discusses ethics in participatory photography with focus on refugee participants and informal refugee camp setting. The paper draws on ethics in participatory photography projects elsewhere and especially the experiences of photographers who work with these methods. The context here is the Calais Jungle camp, where we worked with a group of participants, who were residents of the camp, over several months to encourage photographing and documenting life in the camp and beyond, and to work on life stories that can be drawn from and inspired by these photos. The project, and hence the ethics in our work, were framed by the experiences of the refugee participants, and so at all times we needed to navigate temporality, violence, state oppression, lack of resources, human rights violations, language barriers, religious and cultural differences, national and supranational immigration policies, shame, and more. This chapter discusses how we navigated these ethical issues, the limitations of the approaches and solutions we found, and the lessons we learned, which can be applied to research using participatory visual methods with refugees.
\end{abstract}

Key words: ethics; refugees; photography; narrative methods; participative research

Aura Lounasmaa is a lecturer in Social Sciences at the University of East London. She worked as part of the award-winning team from UEL in the Calais Jungle to teach a university course in the camp in 2015-2016. She currently directs the Erasmus+ funded presessional university course Open Learning Initiative for refugees and asylum seekers in the UK.

\section{a.lounasmaa@uel.ac.uk}

Cigdem Esin is a Senior Lecturer in psychosocial studies at the University of East London and a co-director of the Centre for Narrative Research. Her research focusses on narrative methodologies, multimodal and visual narratives and research ethics.

\section{c.esin@uel.ac.uk}

Crispin Hughes is a photographer who focuses on documenting social issues in the UK and internationally. He has worked in participatory photography with a wide range of communities, including school children in the UK and communities living with HIV in South Africa.

crispinhughes@gmail.com

In 2016 University of East London ran visual story-telling workshops in the Calais Jungle refugee camp. The visual life story workshops were part of a larger education project in the 
camp, through which we encouraged refugees to tell, share, and make sense of their life stories using multimodal narratives. The aim was to facilitate the creation of visual, verbal, written, and processual narratives, respecting their past, their history of displacement, and present conditions, in contrast to the misrepresentation in the media. The edited images and stories were exhibited in physical and online spaces, and many were collated in a book, coauthored by the residents, Voices from the Jungle (Calais Writers, 2017). Crispin Hughes worked on the project as a photographer, Aura Lounasmaa coordinated access to the camp and taught on the other educational projects there, and Cigdem Esin helped design the multimodal perspective and methodology for the project, together with Corinne Squire, who started the project (Esin and Squire, 2013). Various others helped run the projects, which took place over a year in the Calais Jungle, before it was dismantled in the autumn of 2016, and we are grateful for all of them as well as the participants for their contributions.

The project was not framed as research, as we did not wish to become ones who 'take stories' from the residents of the Jungle - already in the public eye, yet unable to set the limits of the representations that are made of them. Instead, we wished to come to the camp with an open mind, offering to those we met there our skills and knowledge through a university course, without any expectations or pressure to produce outputs from the project. Participation was entirely voluntary, and while some participants wanted to share their stories at the end of the project publicly, they did so as authors of their own work rather than as research participants. What we learned through the processes of setting up and running these workshops is applicable to research with refugee communities. It has also greatly challenged our assumptions about what research is, and how we might wish to go about it in the future. The team had worked in various participatory visual projects prior to the Jungle, and the political and ethical boundaries here posed a series of new challenges.

We will begin by explaining the political and psychosocial context of the Calais Jungle at the time of the projects. Due to its geopolitical location, developments in European migration policies and the unique set-up of the camp, a very particular set of issues arose from working with the residents. Our approach is framed by narrative, and particularly multimodal narrative research and visual story-telling. This approach recognises the interrelations that constitute the narratives, including participants' individual and familial stories, their experiences as refugees, as members of transnational communities, and the relations within and across the projects. Using multimodal narratives, a combination of written and visual narratives, within the context of these projects enabled us to facilitate opening up relational spaces for both participants and us. These spaces are shaped by multiple power relations in the field, understood within a Foucauldian framework to include productive consequences, where complex and multi-layered interactions emerged. We will explore what these terms mean in the context of our project. Other theoretical issues important to consider here include decolonising methods and pedagogical practices. We also discuss existing research into the ethics of participatory research with refugees, especially in refugee camp contexts.

The following section of this chapter considers four main problems we faced with the project: 
1) The Dublin accord requires refugees to seek asylum in the first safe country they arrive in. The fear of being returned to France, if they managed to reach the UK, meant participants could not be safely identified as residents in the Jungle. This meant that recognisable selfportraits and authorship of the images and stories had to be erased.

2) Even as participants had fled war, persecution, torture and imprisonment, the Jungle had gained such an infamous reputation that many participants felt compelled to hide the fact they had ended up in this dire situation from their families: instead of using their photos to tell stories of the Jungle, they used them to represent an aspired new life in France. This made it difficult to negotiate common aims for the story-telling, and created issues regarding anonymity and representation.

3) Ownership of photos, stories and cameras remained with the participants throughout, but as each moved on and the Jungle was dismantled, staying in touch with some became impossible. Hence not all voices could be heard/represented. The ethical requirement for continuous consent carries to the present, and the future, and may have implications for both us and our participants that we are only beginning to see now.

4) With all efforts to make the project participatory and decolonise the educational practices, issues of language competency, translation and expert knowledge were present in the workshops. While the aim was to move away from the negative media representations, life stories were still shaped by those who elicited them.

The paper will consider these questions with reference to existing research and the lessons we drew from our own experiences and exchanges with our participants to this date. We draw here from our reflections of the processes and experiences running the programmes, and from publicly available accounts and images, published online or in a book written by Jungle residents and edited by our team, Voices from the Jungle (Calais Writers, 2017). Lastly, we will share our reflections on the unresolved ethical dilemmas and issues to which this project alerted us, and make some suggestions for future participatory photography projects with refugee participants.

\section{Calais Jungle}

In the context of the Jungle refugee camp, the legal and political frameworks that limit refugees' full participation in society also put ethical and practical limits on any type of project that was run with the refugee residents of the camp. In this article, we elaborate on reflections on the collaborative work we did with refugees, and the methodological choices should be discussed in relation to ethical decisions and positions we took while working with participants who have limited access to citizenship rights and information.

As the conflicts in Syria, Yemen, Iraq and various states in North Africa continue over years, a record number of people are displaced either internally, or across continents. This raises a great number of immediate needs to be met, which are often prioritised above the long term 
needs to continue their lives in the settlement countries where they reside temporarily or permanently. Given the acute needs for survival in the camps and during their settlement period, social and educational needs may be viewed as secondary. The importance of education is emphasised for future reconstruction and stability for both conflict regions and post-migration countries (Butler, 2016). Yet, many refugees face barriers of recognition in terms of social and professional qualifications even after their settlement (Houghton and Morrice, 2008). The material conditions in refugee camps and the urge to survive often push refugees to adjust to power relations that shape their everyday lives, leaving their connection to their past and future aside.

Although Calais has been a place where refugees and migrants have gathered to try and cross the English Channel and reach the UK for many years, the recently elevated conflicts and unrest in the Middle East and parts of Africa have severely increased the number of refugees in Europe. In Calais too the number of people regularly awaiting passage across rose from some hundreds in early 2015 to as many as 10,000 in 2016.

We wish to point out here that we are using the term 'refugee' throughout this chapter to refer to participants of the photography workshops we ran in the Calais Jungle in 2016, all of whom were forced migrants and residents of the unofficial camp at some point between 2015 and 2016. The legal term refugee usually refers to those who have already received refugee status and legal protection from a state. This was not the case for most of our participants and students at the time of the photography workshops. Yet, the circumstances of the camp, the migration journeys and the legal constraints of the participants framed the project in such a way as to emphasize the experiences central to their refuge-seeking in the narratives that were produced. The negative press coverage (Finnish Institute in London, 2016), especially in the UK, led Al Jazeera among others to stop using the term migrant to describe those seeking asylum in Europe (Malone, 2015). The term asylum seeker would indicate that all participants had already sought protection, which also wasn't the case at the time of the project, as some were still planning to seek asylum outside of France.

It was this possible future mobility which framed one of the major ethical and safeguarding concerns we had during the photography and writing projects. The Dublin regulation (Regulation 604/2013 of the European Union and the European Commission) stipulates that anyone seeking asylum in the European economic area must do so in the first EU member state they enter. If proof exists that a person has already passed through another member state, they can be returned to that state without the asylum case being considered. Often this proof is fingerprints taken by border agents, but other official documents or even photographs could become the required proof in some instances. Safeguarding the anonymity of our participants was hence a priority at all times.

The so called 'refugee crisis' of 2015 and 2016 was widely reported in European media. Calais Jungle became a favourite destination of UK press due to its proximity, easy access and the sensationalist headlines it promised due to poor living conditions and clashes between camp residents and lorry drivers, police and civilians. Residents quickly learned to mistrust 
the press and others aiming to document lives in the camp. The Jungle also attracted research and other projects focusing on lives of refugees in temporary settlements, which have been proliferated also elsewhere by the rapid increase in populations crossing borders to reach Europe. Documenting refugees' lives and practices has been part of several endeavours which aim to understand conditions of refugees and/or support them in their journeys (see for example Sanyal, 2017). All these projects have been conducted in complex and sometimes difficult and dangerous conditions. Hugman et al. (2011) underline the possibility of putting the refugee communities at risk of harmful research practices under such complex conditions even though such outcomes might be unintended. While following the baseline of 'do no harm' is recognized as a path to follow in work with refugees or other marginalized groups, it is essential to follow a carefully structured ethical-reflexive procedure in order to prevent any outcomes which could make the lives of these groups even more difficult.

\section{Multimodal narratives and visual story telling}

Storytelling has the potential to enable refugee participants to make sense of their lives, to connect their past, present and future while they are in the middle of a crisis. Telling life stories could also provide an alternative to the issue of representation where language and cultural difference remain as a barrier in a historical context in which refugees face hostility, marginalisation and discrimination. We used narrative strategies while working with participants, approaching life narratives in any form (spoken, written and visual) as a tool for the storyteller in the process of self-making and world-making (Bruner, 2003), in response to a network of power relations. For other researchers who work with narratives, it is important to constitute a research process which allows them to listen to the stories, and to interact with the participants in order to explore their meanings and storytelling.

It may be proposed that the creative methods and multimodal narratives expanded the space of the interactions and thus enabled the multiple participants of the projects, including ourselves, to consider the broader context of the asymmetrical power relations in which we lived and worked. Our multimodal approach was shaped by Esin's (2017) previous work with young Muslim women in the UK, where she used the approach to open up creative spaces and narrative construction of the self with these participants. Here young Muslim women came together with the visual artist Chila Burman to create self-portraits using collage. Participants were then interviewed about their collages, and the images themselves included in the analysis as important pieces of the told stories. It is difficult to claim that a power balance shaped the interaction within the space of the projects. It is much more complex. But the creative spaces we managed to open up together with participants of the projects functioned as spaces in which participants were able to express their recognition of otherness but also to challenge the constitution of ideas about "us and them" within the broader relations of power.

Moreover, conversations within these spaces led to further questions around the availability of resources that the participants could use to contest the asymmetrical power relations in which they lived, their access to social and political resources to challenge broader 
inequalities. We considered the space of the projects as a space to hear the 'voice of the refugee/forced migrant', which can challenge the competing voices that come from more socially powerful exogenous agents which may often discount or minimize the refugee experience (Benezer \& Zetter, 2014). In this way, 'the approach [creative visual method] is optimistic and trusting about people's ability to generate interesting theories and observations themselves' (Gauntlett \& Holzwarth, 2006:82). Of course, hierarchies of power and access operated on different levels at all times, and we were aware these intersectionalities and what they meant for our own safety and access to the camp at different times, the stories we would be able to hear and people who would speak to us, and in turn how our participants were differently affected by all this. Emphasis on narrative and visual methods, however, highlighted the participants' agency in choosing what to reveal and to whom.

Visual storytelling reflects social, cultural and political processes, individuals' meanings attributed to their life circumstances and experiences. The visual part of this storytelling practice has the potential to connect (although temporarily) times and spaces in narratives that are otherwise distant (Gastaldo et al. 2012). Researchers who work with refugees have been increasingly using photography as a participatory method. For example, Gomez \& Vannini $(2015,2017)$ used Fotohistorias as a method to examine and map out migrants' perception of home and sense of belonging in Americas in photographs about their experiences of migration. Participants were then invited to take part in interviews focusing on the photos they selected themselves. Gomez and Vannini (2017) argue the three main offers that participatory photography could make as a method while working with migrants: 1) taking and selecting photographs encourage participants to take more control over the information they share through the photographs; 2) photographs can widen the space of research conversation between participants and researchers; 3) producing and discussing photographs could enable participants to externalise their complex emotions, particularly in contexts where they find it difficult to speak up for themselves due to power imbalances.

Barthes (1981 cited in Bignante, 2010) points to the polysemic meaning and interpretations that images could offer. The producers of images could convey uncoded messages and meaning to be deciphered, and these meanings would be multiplied each time a viewer reads/interprets those images. The reading/interpretation of those images mediate the social and cultural narratives through which messages or stories are constituted.

\section{Decoloniality}

Some of us constantly put the focus on life stories under scrutiny: what could telling life stories offer to participants in the context of the camp, which was shaped by multilayered power relations, including multiple forms of racism? But having known that we, as facilitators, educators, collaborators, were part of the same network of power relations as the refugee participants of the projects, we constantly reflected on our own positions and 
engaged in conversations on the ethical dilemmas that we had to deal with throughout the process.

Action research has, from its first introduction in the 1940s, been linked to grand ideas about social change and social justice through emancipatory and collaborative practices (Collier, 1945). In the education sector self-reflection to improve our own educational practices is often the main focus (Corey, 1953), changing the nature of education and educational institutions (Rudduck, 1988) which in turn can has the potential for wider emancipatory developments and social change, as the role of educators, learners and institutions are questioned and analysed and learners empowered to take charge of their education (Freire, 1972). This central aim of empowering learners to move towards social change and equality is at the core of the decolonising project.

As in education, in research and participatory projects the first step in decolonising the process must be challenging knowledge hierarchies through dialogue. Drawing on Riessman's (2008) arguments on the dialogical construction of narratives, we approach the visual stories/narratives as products of an ongoing process of dialogue within the projects, with the broader social, cultural and political narratives. This is an approach to acknowledge the interrelated contexts in which visual stories are co-constructed by the photographer/participants, facilitators and broader audiences. The dialogic approach is significant to make sense of the power relations embedded in the production and consumption of visual stories. It is through those constantly changing relations that stories become strategic tools to negotiate the position of the participants in response to the political context which shape the lives of refugees.

Within the context of the projects, interconnections between the process of construction and re-construction of visual narratives shape the content and message of the images. Visual narratives are constituted by interrelations between individual and cultural geographies (Doloughan, 2006), and as a space for narrative imagination, which involves continuous negotiation and interaction between the self and the other and between personal and collective thinking, not only reaching out to the future but also deeply rooted in the past (Andrews, 2014).

\section{The relationality of Ethics -conceptual-methodological framework}

The narrative approach that we used in several projects that we ran with the refugee-residents of the Calais camp is interlinked with our consideration of narratives as a form of interaction between storytellers and listeners. The stories are co-constructed in a relational process which bring together life experiences and cultural and social resources of both storytellers and the audiences. This interactional process not only opens up a space for the emergence of life stories, but also invites both the storytellers and listeners to explore what is already known to them in relation to themselves and others. This interactional process is very much shaped by the personal, social and cultural contexts in which we live. It is within the same interactional 
context that our practice, communications, actions and ethical positions are constituted. It is crucial to employ a reflexive perspective while creating a narrative of our practice. This means remaining alert to our own positioning while working with camp residents. We recognised our relative power as white, UK-based academic and professional women and man who could move safely in the camp during daylight hours but could not stay beyond sunset. Perhaps the most striking difference between us and the participants was the time they spent waiting to get the UK compared to the one hour it took us on the Eurostar to arrive at London St Pancras station.

Our work had to be grounded in ethical conduct, which would respond to the unpredictability of working conditions while we were at the camp. It was possible to give information to the potential participants about the projects but most of the time it was not possible to provide information about the next stage. This was because most participants did not know whether they would still be in the camp the following morning. New residents and participants arrived daily. Ongoing consent and collaborative planning was impossible in these circumstances and for many people we worked with the project served as a passing distraction. Others, with whom we worked for longer, became embedded in the planning of the online exhibitions and the book, Voices from the Jungle, and remain collaborators to this date. Our ethical conduct pushed us to recognize the limitations of the work and the dilemmas, to be open to engage in conversation. That includes, at times, questioning our sensitivity to the rights, beliefs, cultural differences, power imbalances in patriarchal systems, etc. as has been highlighted by Etherington (2007).

Starting with the question of 'what constitutes ethical research practice?' Guillemin and Gillam (2004) identify two dimensions of ethics: procedural ethics and 'ethics in practice'. Procedural ethics usually involves the procedure to follow to get approval from a relevant ethics committee whereas ethics in practices refers to ethical issues that arise while doing research. While examining the relationship between them, the authors explore the notion of 'ethically important moments' where a decision has to be made in response to an ethical responsibility. These moments may not necessarily be linked to an ethical dilemma. According Guillemanin and Gillam (2004:265), there is a clear response that the researchers could choose in some cases. But there is still something ethically important in those decisions. The ethically important moments emerge within the everyday research interactions, when a researcher has to make a decision when a participant discloses a painful part of their life or when it is essential to respect the dignity of project participants who live in adverse conditions. The authors offer reflexivity as a resource to handle ethically important moments. They approach reflexivity as a process that allows us to consider how our social and political locations affect our practice (274-75). It is a process of critical scrutiny and interpretation of the researcher, participants and the research context. This approach to ethically important moments with the inclusion of a reflexive process into practice is useful when considering ethical questions related to those unanticipated situations and concerns that arise and demand immediate attention in the work we do. 
For us, that involves relational ethics (Ellis, 2017) through which we seek answers to questions such as how to make good interpersonal decisions concerning our responsibilities towards those in our studies, when we ask about traumatic, personal events that engender strong emotions in respondents. Relational ethics recognizes and values mutual respect, dignity, and connectedness between researcher and researched, and between researchers and the communities in which they live and work" (Ellis, 2007, p. 4). The workshop, or indeed the research encounter, should thus become a space in which the focus shifts from finding a solution to ethical problems to asking more and more questions that will help us to build up relations with respect.

Considering ethics as relational requires a systematic examination of the position of the researcher/facilitator. Kofoed and Staunaes (2015) offers ethical hesitancy as a strategy for the researchers in the field when they need to deal with distressed, concerned participants in zones of high intensity. Kofoed and Staunaes (2015) describe moments in zones of high intensity when the researchers are required to make an intervention to solve a problem, to do what is good and take rapid action. In those moments, they suggest, ethical hesitancy may be a more useful strategy. They describe hesitancy as 'a momentary suspension of action due to an embodied sense of thoughtfulness and engaged capability of interrupting one's own immediate incentives to response and enact embedded normativities and judgements' (2015:25). Hesitancy as ethics enables the researcher to consider their long-term contribution to the communities they work with. Instead of contributing to a clear solution, researchers contribute to the development of a solution without rapid intervention.

While equipped with these important approaches to ethics in research, the Jungle and its residents surprised us and caught us off guard more often than we can describe here. While we often wished to pursue photography, story-telling and writing in a structured format, our participants were more eager to converse over tea. Nayeri (2019) discusses the ethical dilemma we face when expected to accept hospitality from refugees who live in deprived conditions. Like Nayeri, we hesitated. Accepting these invitations created a bond of mutual respect and dignity, where other stories, including the visual ones, could also be shared. Our process of working with people in the camp, and our process of working with images and stories produced there are always guided by these theoretical approaches and more, the most important of which was the approach to our participants as fellow humans, learners, knowers and tellers, whom we had the privilege to listen to and to hear.

\section{Challenging representations}

Our aim was never to 'represent' the narratives of the refugees that we work with. The Calais Jungle was already in everyone's consciousness through the press and news coverage it received. We only reached a small number of people in the camp, and any representation would have been limited. It was also impossible to control where such representations would be taken once produced, and how they might be (mis)interpreted. Once narratives are constructed, once we become audience to the stories, once we carry them to different 
environments as the 'voices of refugees from the Calais camp', 'representation' arises as a matter to consider. Indeed, some of our participants were motivated by this possibility to be differently represented through their own visual and written stories. As Shaheen from Afghanistan stated: “...it was interesting to write, especially because I knew that now, many people would read my story" (Calais Writers, 2017, p. 256). The possibility of representing a different point of view and challenging the harmful media representations of the Calais Jungle and its residents was a strong motivation for many participants throughout the project.

The voice of the refugee heard through their life stories is important to document, and through it we can begin to hear the reality of countries of origin and of refuge. Those voices are critical tools in challenging the stereotypical images of refugees particularly in countries of refuge that are created and sustained by media. The life stories are tools for refugees to build up an active stance showing their resourcefulness and motivation. Refugee narratives are also products of the heterogeneity of refugee experiences. The question of representation then becomes one of the many 'ethically important' moments in the project. Dona (2007) points to the essentialist ways of representing refugee voices through binary categories such as victim/survivor, resilient/vulnerable, deserving/undeserving. The narrative approach that we used was helpful in problematising these essentialist ways in which life stories of refugees from the Calais camp were represented in the media. This approach enabled us take a critical position towards the definition of those binary categories and to respect the complex individuality of each life story. Yet, it is not possible to fully control the destination of stories. When we listened to the stories of refugee participants, we heard details of their past life at home, their painful journeys, their life at the camp, their disappointments and friendships, their hopes and plans for the future. Being audience to those stories left us with constant worry about who else would listen to their stories. This is not only a concern about the confidentiality of the content, what and what not to reveal while disseminating stories. Our awareness of the emotional investment that refugee storytellers make in their stories keeps us alerted whenever we share stories.

The participants of photography workshops had an intention to represent the camp conditions in their pictures, as a strategy to communicate with the broader world. Yet, they also had difficulties to frame those representations in attempt to challenge the stereotypes and prejudice attached to refugees and their lives. Drew at al. (2010) underline a similar difficulty that the participants in their health research with young people in which they used visual storytelling as a method. The young participants with chronic illnesses found it difficult to photograph the conditions of their everyday life with illness as they did not know how to deal with the stigma attached to the chronic illness they had. Indeed, many of the photographers in the Jungle moved away from photographing the conditions of their life. Many produced images of an imagined life in Europe, where the Jungle did not exist. Many did this to send proof to families back home that they were doing well. By 2017 the Jungle had become so infamous that participants felt they needed to hide the fact they were living there from their families. As Habibi (from Afghanistan) states: 
My parents are in Afghanistan. I didn't tell them, 'I'm living in the Jungle”. When my mom calls, I say, “Actually yeah, they gave me a very nice house here.' Sometimes they tell me, 'Send me a picture.' I go to a volunteer's house, taking pictures of it, sending them to them. As if I have a really nice house. I cannot tell them the truth, that I'm living the 'Jungle' life. (Calais writers, 2017:116)

In addition to pictures of the nice houses and cars, participants posed for pictures in front of monuments, statues and grand buildings, as if on a holiday touring France. These images were interesting and communicated an important aspect of the imagined and aspiring life stories of the participants, but posed the issue of anonymity and safety of the photographers. How could we anonymise and safeguard the participants while simultaneously respecting their authorship and integrity as photographers?

\section{Decolonising practice, photography and ethics}

Prior to the collaboration between the authors in the Calais Jungle, Hughes had worked in many countries across Asia and Africa as a freelance photographer taking pictures to support the work of mainly UK based NGOs. As part of the practice he was always attuned to the power issues in play in this traditional approach to image gathering, however benign the intention. The ways he attempted to mitigate this was by photographing with consent, gathering names and quotes and asking, 'if I were the subject of this photograph, would I be happy to see it published?' When photographing politicians, military commanders and the like, these concerns were generally waived. Those wielding power can be legitimately held to account in visual or written media. Attempting to manage access to their portrayal is part of their work. The photographer must be wary of manipulation and try to avoid being co-opted into producing propaganda for those in power.

Pittaway et al. (2010) discuss the challenges of using participatory methods in their work with refugee research participants. They question the ethical responsibilities to the stories in research contexts while working with displaced populations, in complex and sometimes dangerous settings. The authors' main concern in posing the questions about what happens to the stories of participants lies in the ethical challenge for the researchers to contribute to the lives of people they work with, recognising them as subjects. Pittaway et al. argue that power imbalances between researchers and participants raise complex questions while working with refugees, as the rights of research respondents who are protected by standard ethics procedure have been designed on the basis of biomedical research which usually take place in isolated, easy to control settings. Refugee participants do not generally have rights over their representation as research participants, or authority to make a complaint.

Anonymity is a particularly difficult issue in participatory photography. Richard Avedon spoke of the photographer and the subject having 'different ambitions for the image'. This transfers to participatory work, where an image may have different meanings and uses for the photographer, an academic researcher, an arts project, or a politically motivated advocacy group. Previously, when Hughes was working with school children on participatory 
photography, the project was framed as an art project and thus there was no suggestion that the children should be anonymised or instructed not to photograph themselves or other people. The idea of documenting a school with no children and families without human faces would have been perverse. Pupils would have photographed each other and their families regardless. The resulting policing of their photos would have been potentially emotionally damaging to the children. Explaining that the sight of their faces was inflammatory or obscene and that a photograph of them would place them in great jeopardy, would have been undermining and confusing. The fear and lack of confidence engendered could have reduced their ability to recognise and manage any issues around paedophilia they might encounter.

In other participatory projects Hughes has worked on, such as Through Positive Eyes ${ }^{1}$, with Gideon Mendel, involving those living with HIV, participants all agreed to photograph themselves recognisably. Where published sets of images did not feature faces this was for aesthetic, not ethical reasons. For example, Anthony in Mumbai used paper cut-out shadow figures to tell the story of his life with HIV. This was simply the strongest and most pared down method of re-visiting past trauma. Taking part in this project clearly exposed participants to the very real possibility of physical attack, abuse or discrimination. Each participant went through a thorough consent process. Volunteers were initially screened by local advocacy and support groups working with the projects. Most people had already openly disclosed their HIV status, and many were activists in the field. All agreed with the tenets of the project, that stigma was at least as dangerous to them as the virus itself and that if people saw their faces presented without shame and heard their stories in their own words then stigma would be reduced.

Risk of violence was also present with the participants in Calais, although participants were already clearly recognisable as refugees to all those who were exercising violence in the camp. The consequence of being recognised as a resident of the Jungle posed the biggest risk for those participants who had not (yet) sought asylum in France. Under the Dublin Agreement fingerprints can be held on record for five years before any records must be destroyed. Although some participants were planning to remain in France, they had to wait for a period of time after having been fingerprinted in Bulgaria, Greece, Serbia or elsewhere before presenting their cases. Others were still hoping to move elsewhere in Europe, including the UK. For them the risk of being recognised from photos, especially any which were published, could have meant being returned to France after succeeding in the perilous journey across the English Channel. Some participants also wished to hide the fact they were living in the Jungle from their families, and indeed risk of violence towards families who stayed behind was something that could not be predicted, in cases of some participants, had they been shown to be in Europe. It also wasn't possible to predict whether all participants

\footnotetext{
${ }^{1}$ Crispin Hughes and Gideon Mendel have worked with HIV+ve adults in a new worldwide project managed by the UCLA Art and Global Health Center. Despite its academic base Through Positive Eyes was conceived from the start as an advocacy project combating the stigma of HIV: 'Through Positive Eyes is an attempt to address key themes of the AIDS epidemic: widespread stigma, extreme social inequality, and limited access to lifesaving medication. The project is based on the belief that challenging stigma against people living with HIV/AIDS is the most effective method for combating the epidemic - and that art is a powerful way to do this.' (https://throughpositiveeyes.org/about)
} 
would be able to stay in Europe, and what the consequences might be if some had returned to their countries of origin with photographic evidence of their stay in Europe available publicly.

With due consideration and consultation with experts, we felt that the choice to be shown, where legal status had not yet been achieved, was too great to waive. The authorship of participants and their own choices of representation were severely limited by the fear of legal consequences for the participants. Participants remained the owners of their photos, and often posted them in social media accounts at the same time as the team was carefully removing them from other public sites. We were simultaneously trying to come up with ways to respect authors' choice of topics and representation while anonymising the pictures. Participants were guided to exclude faces from their photos and photograph backs, hands, shadows and outlines instead. When a face was included, Hughes experimented with anonymising techniques. Both pixilating the face and covering it with a black bar seemed to draw parallels to representation of criminals in popular media and were immediately abandoned. Instead, Hughes faded the authors' faces from the image, making them appear transparent against the background. On reflection this seemed just as bad a solution. Authors, already rendered voiceless through media who presented them in a negative light, were once again erased from their own stories. While this technique did not evoke the same connotations of criminality as others, it rendered the refugee participants invisible, leaving them to haunt the beautiful European city in which they posed, which in real life was ignoring their lives and rights and erasing their humanity.

This contradictory and complex process of anonymising while respecting authorship and author choices of public display of photos could be seen as paranoid. Indeed, social media and photographs are rarely used as evidence in Dublin returns. To our best knowledge, no participants' details or images produced during the project were used against them in legal proceedings, and this renders the process worthwhile, even if it was indeed futile. Most of the authors have now gained safety and are able to reclaim their work from the project, if they so wish. With the help of the anonymity during the project, they can also leave the photographs, the stories, the project and the Jungle behind without the fear that it will come back to haunt them through these images. But only if the images themselves are also left behind, and do not continue to come back on the pages of newspapers, websites and methodology books.

\section{Consent and ownership}

Having discussed representation, power, and coloniality, we wished to prioritise ownership and consent throughout the project. Consent and ethics procedures in the social sciences have largely been lifted wholesale from the medical field. In medical trials there is a real need to anonymise data, not only to protect patient's medical records from being made public, but also to keep the trial blind and prevent bias on the part of the researchers. 
We had avoided projects in which disposable film cameras were handed to NGO beneficiaries as being gestural and infantilising. All control would remain with the NGO and its foreign staff. The cameras implied that the beneficiaries' pictures would be low quality and disposable, and that they could not be trusted with a real camera. Disposable cameras are collected at the end of a project and kept by the organisers, who do not need to continue their relationship with the participant after this point. Participants may never get to see their own photos once they have been developed. This highlights the participants' own disposability, already at the forefront in the Jungle. Indeed Hagan (2018) found that refugees in Calais were quick to turn down such an approach.

The advent of good quality, affordable, digital cameras presented an opportunity to properly up-end, or at least destabilise, the power relationship between photographer and subject. Ownership of the digital cameras and the memory cards, as well as the promise of a future ownership of these photos marked the participants as authors from the beginning. The issue of ownership is rather problematic in the context of the Jungle. In addition to the invisibility and lack of rights which frames the refugee experience in camps, the Jungle, as an unofficial camp, provided no security or right to property for the residents. Many residents left the camp every night to make the $7 \mathrm{~km}$ walk to the Calais port to 'try' for England. Anyone who didn't return within 12 hours was assumed to have left, both by the authorities and other residents. The container camp run by the French state imposed a 12-hour absence rule, after which individual's possessions would be removed and destroyed, monitored by automatic gates using a fingerprint as access key. Little could be 'owned' by anyone living in this situation. Hence, any discussion by us of participants 'owning' their photos was limited.

Crucial to our method is the editing process. Digital cameras offered a chance for subjects to become participants. If the images were not only taken by the participants but also seen, edited and captioned by them, then surely ethical and consent issues could be completely side-stepped. Levels of confidentiality, respect for privacy, notions of taste and style could all be set by the new photographers. The aesthetics of colonial inquiry, traditional anthropology, and ideas of the exotic which any photographer couldn't help bringing to bear on their subjects would all vanish in a puff of digital smoke. We cannot pretend that the images produced present the most plural and diverse range of truths that would be desirable. There were no female photographers and some participants had already been exposed to photography as an art form, and hence its traditional focus and preference for male gaze (Berger, 1972). Once it became apparent that some of these photos would be seen by wide audiences who could access them online as well as the readers of Voices from the Jungle, questions of the gaze, representation and authorship needed to be revisited. What kind of narrative were we (co-)producing if all we showed was squalor? Yet, as Dodd and Jackson (2019) argue, as editors of the book and the online exhibitions we were the ones to ultimately decide what "good" photography from the Calais Jungle looked like.

When working in schools, Hughes and Mendel had involved the children in the editing at all stages. Each child had an initial one-to-one session to look at all their images. These images then went to a final group edit with the whole class. This developed their critical skills and 
self-esteem while promoting understanding of different lives and cultures within the school. The images, and short extracts written about them, including poems, were used and displayed in a variety of ways: exhibited in galleries, in multimedia videos, in curriculum development and in print. In the Jungle the opportunities for this level of participation were limited, but where possible, photos were selected with participants either in person, or at later stages via email.

Consent was discussed from the beginning of the project with participants, with each taking different levels of interest in the process. In addition to discussions regarding anonymity, participants were informed the photos would remain theirs, and consent would always be sought if photos were to be used. Consent and ownership continue to play out in complex ways outside of the camp. Pittaway et al. (2010:233) identify a potential issue in the dissemination of the findings of research with refugee participants. That is the desire of refugees themselves to have their stories told to the international community without considering potential harmful effects of those stories to themselves and their communities. Consent is also always given at a specific time. Here, that time was when participants were still living in the Jungle, or where they had recently left it. Once participants moved on and made lives elsewhere, the consent received at that time is no longer satisfactory. Assuming participants continue to wish to be represented as refugees and as residents of the once infamous refugee camp risks locking them into a static refugee identity.

We still believe that participatory photography is capable of producing far more challenging and interesting images than the traditional lone photographer. But the interplay of consent, power, distribution, control and anonymity has become more complex. As a tool for academic research or for advocacy it is now much less amenable to a tick-box ethics committee approach. The UK-based ethics committee is now attempting to police images which are no longer produced by its employees. If a refugee takes a heartfelt but sexist photograph, then the foreigners may step in and delete or suppress it - thus restoring the old power relation. In long-term educational projects these questions can be addressed through dialogue, whereas in the temporary refugee camp setting the space for these dialogues was limited.

\section{Conclusion - relationality of ethics}

The camp was dismantled and the more than 8,000 people living there by October 2016 dispersed to locations around France. While the conditions in the camp had been inhumane, the demolition of it presented new problems. When dispersed into small communities, refugees have little access to cultural and educational initiatives. Those who felt they would not qualify for asylum in France have fled into other countries or are staying outside official accommodation. Calais has been a crossing point for the UK for many decades; people still arrive. Without the camp, there are approximately 500 refugees staying in Calais intermittently, trying to cross to the UK. They are harassed by the police at food collection 
points, kept from sleeping in large groups and are unable to establish any shelters or abodes, however temporary.

Listening became the most important ethical and decolonial practice in these educational and story-telling processes. If we understand life to provide materials for narratives, we can embrace the multiplicity of the possible narratives that can be told. As Meretoja (2018: 27) tells us, narrative is 'ethically loaded precisely because it is a way of making sense of our being in the world'. Our participants and co-authors continuously challenged our assumptions about ethics and representation. While we were at times overly concerned about the Dublin Accord and its consequences, our participants held insider knowledge about its inner workings that we did not have access to. For them, concerns about family back home were often more important; not wanting anyone to know they were 'living the Jungle life'.

Two years after the end of the project and publication of the book Voices from the Jungle, new challenges have emerged. On-going consent and difficulties to remain in touch with participants to reinstate this at every new public communication can stagnate discussions and dissemination. As participants have moved on with their lives, most with a significantly improved membership of their new European states, constantly asking them to return to the Jungle through these discussions is a new form of violence. Some are willing and eager to continue the conversations we started nearly four years ago. Others are not. Stigmatisation of migrants and refugees continues in public discussions and the media, and as our authors have been given an opportunity to move on, emailing or texting any of them, yet again, just asking if we can show that image again; include their name again; bring them back to the Jungle makes my heart heavy. For this reason we have struggled with the decision of whether to include photos in this chapter. Contacting, out of the blue, asking for permission, discussing which photo to include, cannot be undone once we start the conversation. We become the ones to transport the original meaning to new, unknowable locations. We simultaneously transport all of us - ourselves, the authors and our audiences back to the Jungle, which now has gained a new meaning for all of us. Every time an invitation comes to go talk to a newspaper or a conference audience about 'what it was like', we wish to prioritise the voice of the participants. Every time, we also want to give the participants a chance to move on and leave the Jungle behind.

\section{References}

Andrews, M. (2014). Narrative imagination and everyday life. Oxford: Oxford University Press.

Benezer, G. and Zetter, R., (2014). Searching for directions: Conceptual and methodological challenges in researching refugee journeys. Journal of Refugee Studies, 28(3), 297-318.

Berger, J. (1972). Ways of seeing. London: Penguin Books 
Bignante, E. (2010). The use of photo elicitation in field research: exploring Maasai representation and use of natural resources. EchoGeo 10, Retrieved from https://journals.openedition.org/echogeo/11622 [accessed 22/4/2019]

Bruner, J. (2003). Making stories: Law, literature and life. Harvard.

Butler, J. (2016). Frames of war: when is life grievable? London: Verso.

Calais Writers. (2017). Voices from the 'Jungle'. London: Pluto Press.

Collier, J. (1945). United States Indian Administration as a laboratory of ethnic relations. Social Research 12(3), 265-303.

Corey, S. M. (1953). Action research to improve school practices. New York: Bureau of Publications, Teachers College, Columbia University.

Dodd, S. and Jackson, A. (2019). "Good" photographs: the white male gaze and how we privilege ways of seeing. Witness. Retrieved from https://witness.worldpressphoto.org/goodphotographs-the-white-male-gaze-and-how-we-privilege-ways-of-seeing-30ac3f005acc [accessed 1 September 2019].

Doloughan, F. (2006). Narratives of travel and the travelling concept of narrative: genre blending and the art of transformation. The Travelling Concept of Narrative, 1, 134-144.

Doná, G. (2007). The microphysics of participation in refugee research. Journal of Refugee Studies, 20(2), 210-229. Retrieved from https://doi.org/10.1093/jrs/fem013

Drew, S.E., Duncan, R.E. and Sawyer, S.M. (2010). Visual storytelling: a beneficial but challenging method for health research with young people. Qual Health Res. 20(12), 167788. doi: $10.1177 / 1049732310377455$.

Ellis, C. (2017). Compassionate Research: Interviewing and Storytelling from a Relational Ethics of Care. In I. Goodson, M. Andrews, and A. Antikainen (Eds.), The Routledge International Handbook on Narrative and Life History (pp. 431-445). Routledge.

Esin, C. (2017). Telling stories in the pictures: Constituting and processual and relational narratives in research with young British Muslim women in East London. Forum Qualitative Sozialforschung/Forum: Qualitative Social Research, 18(1). Retrieved from http://www.qualitative-research.net/index.php/fqs/article/view/2774/4063

Esin, C. and Squire, C. (2013). Visual autobiographies in East London: Narratives of still images, interpersonal exchanges, and intrapersonal dialogues. Forum Qualitative Sozialforschung / Forum: Qualitative Social Research, 14(2), Art. 1.

Etherington, K. (2007). Ethical Research in Reflexive Relationships. Qualitative Inquiry, 13(5), 599-616. 
Finnish institute in London and the Finnish Cultural Institute for the Benelux. (2016).

Refugees and asylum seekers in press coverage. Retrieved from https://www.fininst.uk/wpcontent/uploads/2017/11/Refugees_and_asylum_seekers_in_press_coverage.pdf [accessed 22/4/2019]

Freire, P. (1972). Pedagogy of the oppressed. New York: Herder and Herder.

Gastaldo, D., Magalhães, L., Carrasco, C., and Davy, C. (2012). Body-map storytelling as research: Methodological considerations for telling the stories of undocumented workers through body mapping. Retrieved from http://www.migrationhealth.ca/undocumentedworkers-ontario/body-mapping [accessed 22/4/2019]

Gauntlett, D. \& Holzwarth, P. (2006). Creative and visual methods for exploring identities. Visual Studies, Journal of the International Visual Sociology Association, 21(1), 82-91.

Guillemin, M. and Gillam, L. (2004). Ethics, reflexivity, and "ethically important moments" in research. Qualitative Inquiry, 10(2), 261-280.

Gomez, R. and Vannini, S. (2017). Notions of home and sense of belonging in the context of migration in a journey through participatory photography. The Electronic Journal of Information Systems in Developing Countries, 78(1), 1-46.

Hagan, M. (2018). Capturing the Invisible: The Challenges of Using Photography as Method with Asylum Seekers Living in Calais, France. Retrieved from https://www.law.ox.ac.uk/research-subject-groups/centre-criminology/centrebordercriminologies/blog/2018/10/capturing [accessed 22/4/2019]

Houghton, A-M. and Morrice, L. (2008). Refugees, asylum seekers and migrants: steps on the education and employment progression journey. National Institute of Adult Continuing Education.

Hugman, R., Pittaway, E. and Bartolomei, L. (2011). When 'do no harm' is not enough: The ethics of research with refugees and other vulnerable groups. The British Journal of Social Work, 41(7), 1271-1287.

Kofoed, J. and Staunæs, D. (2015). Hesitancy as ethics. Reconceptualizing Educational Research Methodology, 6(2).

Malone, B. (2015). Why Al Jazeera will not say Mediterranean "migrants". Al Jazeera. Retrieved from https://www.aljazeera.com/blogs/editors-blog/2015/08/al-jazeeramediterranean-migrants-150820082226309.html [accessed 5/4/2019]. 
Meretoja, H. (2018). The ethics of storytelling: Narrative hermeneutics, history, and the possible. Oxford University Press.

Nayeri, D. (2019). The ungrateful refugee. London: Canongate.

Pittaway. E., Bartolomei, L., and Hugman, R. (2010) "Stop Stealing Our Stories": The Ethics of Research with Vulnerable Groups. Journal of Human Rights Practice 2(2), 229-251.

Riessman, C. K. (2008). Narrative Methods for the Human Sciences. London: Sage.

Rudduck, J. (1988). Changing the World of the Classroom by Understanding It: A Review of Some Aspects of the Work of Lawrence Stenhouse. Journal of Curriculum and Supervision, $4(1), 30-42$. 